\title{
Epistemic Proceduralism, Capabilities and Rights: An Approach from the Perspective of Amartya Sen
}

\author{
Soledad Analía Pérez \\ National Scientific and Technical Research Council (CONICET), Argentina
}

Copyright $\bigcirc 2017$ by authors, all rights reserved. Authors agree that this article remains permanently open access under the terms of the Creative Commons Attribution License 4.0 International License

\begin{abstract}
This paper expounds an exploratory study on the connections between Amartya Sen's capability approach and epistemic proceduralism focused on the measurement of poverty. The study describes the general features of Sen's approach and then analyses them from the perspective of epistemic proceduralism. Some difficulties were observed in the deliberative concept of democracy and the process of devising lists and consensuses to design tools for poverty measurement. We proved that the strongest link between the capability approach and epistemic proceduralism lies in the theoretical level. Therefore, whoever studies poverty and social needs has to cope with the challenge of applying the ideal of deliberative democracy to the definition of needs or lists of capabilities and provide arguments to ground rights.
\end{abstract}

Keywords Poverty, Capability Approach, Democracy, Epistemic Proceduralism, Measuring Instruments

\section{Introduction}

It proves impossible to ignore the impact caused by Amartya Sen's capability approach on the theoretical and methodological levels in studies of poverty. Understanding poverty as a deprivation of capabilities spelt a conceptual fracture. It introduced a notion that focused on the agent and on each person's freedom to lead the life he values. It questioned the standard strategy of prescribing a list of "necessary" goods. Sen has held that if measuring instruments are to be deemed legitimate, processes of selection such as those involved in creating lists of valuable points must involve the practice of reasoning that should follow democratic procedures.

In connection with this, several authors who endorse deliberative approaches to democracy hold that deliberative processes involve cognitive virtues. This notion is known as epistemic proceduralism. The purpose of this paper is to analyse the connection between the capability approach and epistemic proceduralism. It hopes to explore a line of research that has not been sufficiently developed yet. It aims to grant legitimacy to instruments of measurement, involving various agents (and not exclusively experts). It also expects legitimacy will not rest exclusively on the process; rather it should focus on the cognitive extra feature that may result from public debate.

Consequently, the process will be as follows: first it will sketch out the general features of the capability approach. After that, the capability approach will be analysed under the light of epistemic proceduralism, identifying features or reasons that may account for a link between Sen's work and the deliberative conception of democracy. Lastly, I will point at some concerns that arise in the deliberative concept of democracy as well as in the process of consensus building around the valued-valuable when devising instruments to measure poverty. Despite these difficulties, I believe the proposal is promising.

\section{A Characterisation of the Capabilities Approach}

\section{Poverty as Capabilities Deprivation}

The conceptual break ${ }^{1}$ brought about by the capability approach in the definition of poverty is linked to the emergence of a new strategy in the evaluation of wellbeing. Such strategy focuses on the possibilities for action enabled by the possession of goods. Within this framework, freedom holds a privileged position in the definition of welfare. The notion of capabilities lies between the subjectivity of preferences and the objectivity of needs, witnessing to the

\footnotetext{
1 It is relevant to clarify that when we state that the introduction of the notion of capabilities caused a conceptual break, in no way are we limiting this type of processes to the belief that one individual author is able to introduce new meanings in the language of a particular period in history. Rather, we are inclined to hold the need to think about the contexts of debate and the premises shared with the members of the community involved, concepts that open interactive processes between opposite stances that provide the necessary framework for certain conceptual transformations to become viable.
} 
freedom a person has to develop the kind of life he values. Consequently, the value of a life style depends on the freedom to choose it enjoyed by the agent.

The basic notions of Sen's approach are functionings and capabilities: the former are a person's states and actions, while capabilities are the various combinations of functionings that a person can attain. Achievements identify valuable objects, while capabilities determine the value each person allots to the entire set of such achievements (Sen, 1997).

An individual's capabilities and functionings are interrelated but they differ. Functionings are achievements, while a capability is the ability to accomplish it. The connexion between functionings and life conditions is more direct that is the case with capabilities, which are linked to the notion of freedom. Conditions involve processes that ensure freedom of action and decision as well as the opportunities enjoyed by individuals in view of their personal and social circumstances. From such perspective, knowing which goods a person owns or may use is not enough to know which functionings he may attain. Consequently, it is necessary to have a much fuller knowledge about the individual and his life circumstances in order to determine what capabilities and functionings he may achieve.

The capability approach does not consider the functionings a person has achieved as the ultimate normative measure. Interest is focused on people's freedoms, that is, on their capability to function and on the levels of functionings attained.

The process of conceptual change we mentioned above implied a greater complexity in the interpretation of goods. In Sen's view, a large number of personal and social factors are at play between goods and what can be achieved with them. This results in significant differences in the final result between the achievements of various individuals. From Sen's perspective, the main feature of welfare is what a person can "achieve", broadly understood. When discussing achievements, Sen mentions "several ways of doings and being" (Sen, 1997: 77). They may be activities or states of existence or of being. Among the former, we find: eating, reading, seeing; among the latter, situations as being well nourished, enjoying good health, not feeling ashamed of the clothes worn, etc. The central point is that people should be free to develop the type of life they wish. Development and wellbeing are analysed in a comprehensive and integral way; attention is paid to the connections between material, mental and spiritual wellbeing, as well as the economic, social, political and cultural dimensions of life.

Sen's proposal aims at devising instruments to assess individuals' quality of life without falling into reductionisms by sticking to material resources or welfare. That is why his approach takes both functionings and capabilities into account. It is worth mentioning that functionings display the situation people are actually experiencing, what they are, what they can or cannot do, and their rights are connected along this line. A person's capability is given by the number of alternative vectors of functioning modes he/she might achieve; in other words, that person's possible development alternatives connected to freedom in a positive sense. Whereas capabilities, in the plural, refer to particular functionings potentially attainable by an individual, such as the capability to enjoy good health, a good education, being well nourished and the rights associated with them.

In Sen's view, poverty must be conceived as capability deprivation. Being deprived is not tantamount to lack of capabilities. When Sen discusses capability deprivation, he thinks of the suspension of people's potentials, the suspension of certain capabilities that are present but cannot flourish or develop on account of various conditioning factors to which individuals are submitted: disease, scarce or non-existent income, unemployment or lack of education, among others.

Along the same line, Sen focuses on the importance of certain liberties in the enhancement of people's lives. Conspicuous among them are basic capabilities: avoiding situations of undernourishment, preventable morbidity, and premature mortality. Also, freedoms connected with the capacity of expression, reading, writing, calculation or active participation in politics (Sen, 2000).

Consequently, these elementary capabilities and the freedoms associated with them are not merely instrumentally important. Their relevance does not lie on the fact that their absence would curtail other achievements, but on the fact that they are constitutive to development. "Considerable attention must be paid to social factors, including State interventions, which contribute to determine the nature and reach of individual freedoms. Social institutions can make a crucial contribution to guarantee and increase the freedoms of individuals' (Sen, 2000: 61).

The passage quoted denotes that, in Sen's opinion, individual capabilities largely depend on economic, social and political systems. Following the line of his argument, individuals must be seen as agents who actively participate in the design of their own lives if they have the necessary opportunities to do so. Such opportunities are not alien to the role played by the State, institutions and society in protecting and strengthening human capabilities. "Their role is to help, not to provide something ready-made" (Sen, 2000: 75).

In this sense, in the analysis of poverty, the capability perspective contributes to a better understanding of the nature and causes of poverty and deprivation by shifting the core of attention from the means (and a particular means that usually gets exclusive attention: income) to the ends that individuals have reasons to pursue and, consequently, to the freedoms that are necessary to accomplish those ends (Sen, 2000: 117).

The connection between income poverty / capabilities poverty is given by the fact that income is a means to achieve capabilities, but increasing income is not the end to which 
policies aimed at reducing poverty should be directed. Consequently, in Sen's opinion, assessment processes should focus on fundamental freedoms. Since the purpose is to focus on the individual's opportunities to achieve his aims, it is important to take into account the goods agents have at their disposal as well as the personal features that contribute to determine the process of converting goods into achievements. Illness or advanced age may seriously undermine the chances of leading a normal life, even when the number of goods owned is larger compared to those of a young and healthy person.

This is where, according to Sen, the notion of functionings/achievements becomes important since it shows "the things a person may value doing or being" (Sen, 2000: 99). Valuable achievements cover a wide range that goes from elementary things such as eating or not enduring avoidable illnesses, up to activities or personal states such as self-respect or participating in communal activities. " $A$ person's capability refers to the various combinations of functionings he may achieve... it is a type of freedom: the basic freedom to achieve different combinations of functionings" (Sen, 2000: 99-100). It means the freedom to choose the life-style one wishes to lead.

From this perspective, analysis may focus on the functionings achieved, viz. what the person effectively managed to achieve, or on the set of capabilities, options and opportunities available for any individual. Consequently, the approach offers the possibility of achieving two kinds of information: about the things a person does and those he has the freedom to do.

\section{The Process of Drawing Lists of Capabilities}

Besides introducing a new notion that focused on the agent and each person's freedom to lead the life he values, Sen questioned the customary strategy of prescribing a list of needs, goods or, in the case of his approach, capabilities. The term "prescription" is not trivial and somehow anticipates the importance Sen grants to the process of selecting a list of capabilities. Precisely, one of the main virtues he grants to the approach is the fact that it is open: he believes openness contributes to bring arguments, presuppositions and criteria to the fore around the definition of functionings and capabilities that should be included in a list. In this way, he rejects the practice of adopting an "implicit model" that conceals them. Sen questions the reification or fetishization of a list that may be adapted to different contexts, overrating the instrument above the context and the subjects on whom it is applied.

Sen grants crucial importance to the process of choice and the freedom of thought implied in the selection of relevant capabilities. From his perspective, it is necessary to follow democratic processes; consequently, prescribing a list would go against one of the principles of his approach, namely, the need to expand freedoms (Sen, 2000).
Resuming Sen's words, assessments like those involved in poverty studies require "some kind of reasoned 'consensus' on weighting or at least on a range of weightings" because they are exercises of social choice that require "a public debate and democratic understanding and acceptance" (Sen, 2000: 104).

This leads him to state there is some tension between the various strategies used to select weightings. He stresses the need to explicitly ascribe value weightings to the different components of the quality of life and discuss the weightings chosen in public debates and critical scrutiny.

There $[\ldots]$ is an interesting option between "technocracy" and "democracy" in the selection of weightings [...]. A selection procedure based on a democratic search for an agreement or a consensus may prove extraordinarily cumbersome and many technocrats are sufficiently disgusted with its complexity as to yearn for some magic formula that will simply provide us with ready-made weightings that will prove "perfect". Obviously, however, there is no such magic formula because weighting involves evaluation and valuing: it is not an issue of impersonal technology (Sen, 2000: 104).

In fact, according to Sen, people's values must be taken into account to establish which accomplishments must be included in a list. Pulling down disciplinary chasms, Sen holds that studying cultural processes may contribute to understand guidelines of behaviour, social capital and economic success. Values are passed down, and culture, in his opinion, is a dynamic construction that includes actions of emulation and imitation. Therefore, it is imperative to study the process of value formation and transformation, analysing how they are modified and connected to other values and cultures (Álvarez, 2008).

Consequently, though there may be a consensus about the capabilities to be included in a list, when it comes to comparing between individuals and devising policies, it is crucial to take into account how people value functionings and prioritize consensual accomplishments.

(...) if prior to any evaluation it is essential .... to carry out a documented public scrutiny, implicit values must be described more explicitly instead of protecting them from scrutiny with the spurious excuse that they are part and parcel of an "already standing" measure that society may use with no previous analysis (Sen, 2000: 106).

The crucial point is to assess if some evaluations may apply or refrain from applying some criteria that have a greater support in public opinion than the sole indicators usually recommended for allegedly technological reasons -such as real income indicators. This proves essential when economic and social policy must be evaluated (Sen, 2000: 107). 
Precisely this search for criteria backed by public opinion takes us back to deliberative views of democracy, and more specifically, to epistemic proceduralism. In what follows, we will describe the general features of that approach. After that, we will go through Sen's work in search of components that might allow us to articulate his proposal with lines of thought that attribute cognitive value to deliberative procedures.

\section{Epistemic Proceduralism and Definition of Capabilities}

The epistemic value of democratic procedures is one of the tenets shared by authors who uphold deliberative approaches to democracy (Gutmannand Thompson, 1996; Nino, 1997; Barber, 2004; Habermas 2009; Estlund, 2011).

To date, there is no monolithic theory about the meaning of the deliberative democracy ideal. Having said that, in the present section we will propose some ideas that may help us to understand the notion of deliberative democracy and the grounding of the epistemic value attributed to it.

Deliberative approaches presume that decision-making must be principally based on deliberation. At the same time, they share an anti-elite concept of democracy: this implies rejecting the belief that one group of people may be better trained than others to decide impartially in the name of all others. From their perspective, the logics of politics differ from that of the market, where individuals choose courses of action according to how they feel individually touched by their decisions.

Supporters of the epistemic character of democracy hold that citizens trust the democratic process of decision making, not only because they deem it more just but also more correct. Along this line, they believe that these processes create a collective action dynamics, characterised by a greater tendency to prefer impartial decisions. This distinguishes them form other alternative decision- making processes (Gargarella, 1995; Estlund, 2011). Such dynamics is generated by the participation of every citizen in the debate, where each one has an equal chance to inform the others about his interests. In addition, any decision that is forwarded must be justified.

There are differences among thinkers who hold a deliberative perspective of democracy about the criterion on which they base epistemic value. While for some it is participation (Barber, 2004; Nino, 1997; Fung and Wright, 2003) and they judge that when more individuals participate in deliberative processes the chances to arrive to the truth are higher. For others, correct decisions do not depend on the number of participants in discussions, but on the conditions under which they are carried out (Habermas, 2008 in Habermas 2009; Rawls, 2002; Gutmannand Thompson, 1996; Richardson, 2002; Christiano, 1996; Dryzek, 2001).

The latter are particularly concerned about the material restrictions involved in any deliberative process: conditions of time and location of the discussions. Consequently, while the first group promotes direct participation of citizens through procedures of political decentralization, the second one stresses the need of reasonable conditions to ensure deliberation.

Despite these differences, those who hold the epistemic vision of democracy find the cognitive value of democratic procedures in a series of factors that, following Pérez Zafrilla (2009), we may summarise as follows:

a) Deliberation increases available knowledge and reduces cognitive asymmetries since it favours information exchange on interests and needs of those concerned by the decisions.

b) It permits the expression of individuals' preferences, interests and needs, which allows them to reinterpret different stances after listening, understanding and interpreting the views of others.

c) It allows detecting and acknowledging mistakes.

d) Screening acceptable reasons will allow individuals to face their own prejudices and value the opinions of others.

e) Manipulation of information becomes more difficult since it enables its distribution, circulation and interpretation by a large number of agents.

f) The inclusion of diverse perspectives implies a greater possibility of avoiding cognitive mistakes and biases typical of homogeneous situations

In view of these issues, supporters of deliberative democracy hold that it is more probable to arrive at correct decisions through processes of public deliberation than through processes that admit negotiation, manipulation or demagogy.

Backing these notions, in "Does democracy still have an epistemic component?" Habermas (2009) showed that several research projects provide empirical proof of the idea that political discussions have a cognitive potential. He stated that numerous studies based on group discussions, which were subjected to measurement and they showed there was acquisition and increase of knowledge, proved opinions were altered and corrected. Consequently, the difference between initial and final discussions may be interpreted as the result of learning.

\section{The Capability Approach under the Light of Epistemic Proceduralism}

In view of these arguments, Sen's proposal proves interesting: to apply democratic procedures to work out lists of capabilities and/or valuable functionings. Not merely in order to ensure another kind of legitimacy for poverty-measuring instruments, but also for epistemic reasons. Sen himself acknowledges the epistemic productivity that democratic practice offers to citizens in the process of values and priorities formation. As implied in his words: "the practice of democracy gives citizens an opportunity to learn from one another, and helps society to 
form its values and priorities. Even the idea of "needs," including the understanding of "economic needs," requires public discussion and exchange of information, views, and analyses" (Sen, 1999: 10).

Sen also holds that:

Our conception of needs relates to our ideas of the preventable nature of some deprivations and to our understanding of what can be done about them. In the formation of understandings and beliefs about feasibility (particularly, social feasibility), public discussions play a crucial role. Political rights, including freedom of expression and discussion, are not only pivotal in inducing social responses to economic needs; they are also central to the conceptualization of economic needs themselves (Sen, 1999: 11).

On this issue, Sen highlights the de-naturalising potential of public discussion when defining needs/capabilities/functionings or valuable life-styles. In Sen's view, discussion and dialogue are indispensable not merely to delineate responses (by which he means public policies) but also to conceptualise needs. The generative process is essential in creating values and may not be seen as alien to political debate. This means it does not depend on whether interchange and public discussion are allowed or not. This proves the performative power of language in the definition of 'necessary' and 'valuable'. Along the same line, implementing the deliberative paradigm may contribute to de-naturalise some situations of extreme deprivation ${ }^{2}$-that may lead to a defensive adaptation of expectations- and consequently posit new valuable lifestyles that would have been unthinkable without public interchange ${ }^{3}$.

Along the same line as Sen, Sandel states that in public deliberative situations a cognitive agency is developed that creates a reflexive distance related to individual and social features. Those features are determined by historical identities, traditions and habits. This allows the "I" to focus on itself, research in its constitutive nature, its various links and acknowledge its demands, until it attains a less opaque self-understanding. This understanding is never fully transparent, the idea is to keep participating gradually in constituting one's identity (Sandel, 2000).

On the other hand, deliberative spaces create horizons where it is possible to cope with "adaptive preferences" (Elster, 1998), viz., preferences formed unconsciously in the face of the difference between possibilities and desires. This process is also known as "sour grapes" in reference to $\mathrm{La}$

2 Sen mentions the case of the Indian state of Kerala, where there was a decline of fertility rates through the emergence of new values, a process in which political and social dialogue played a key role (Sen, 1999).

3 The absence of public interchange may be connected to the notion of isolation described by Arendt. Such situation cancels the possibility of working together in the political sphere and this annuls the capacity of action that is possible in the public space. In this sense, Arendt holds that isolated men lose freedom, they lack a common project and they can only preserve their public life (2008).
Fontaine's fable about the fox and the grapes. The fox wishes to eat some grapes that she could not reach. After several failed trials she comes to the conclusion that she does not mind not reaching them because they were surely sour. As happens in the fable, adaptive preferences are characterised by the development of unconscious strategies that avoid or diminish frustration that might ensue from cognitive dissonance, which occurs when some needs or desires cannot be fulfilled (Pereira, 2007).

In Sen's view, sticking to a fixed list and not creating deliberative spaces to select a list would somehow mean adapting to deprivations. If agents are asked separately about what they deem is a valuable life, they are denied the possibility of progress in social understanding and those instruments are deprived of the wealth that public discussion might provide. ${ }^{4}$

What has been said so far proves that Sen's critique is not opposed to the lists themselves; rather it targets their reification, the fact that they arise exclusively from experts' voices, with no submission to public reasoning. He disagrees with depriving them of the cognitive potential that they might receive as a result of the participation of an array of voices in the definition of what should be included in a list, and why.

This is a crucial point that indicates the connection between epistemic proceduralism and Sen's proposal. Whereas Development and Freedom exhibits concern about the procedural issue -basically, concern to grant legitimacy to poverty-measurement instruments- other works demonstrate that such legitimacy does not rest exclusively on ensuring a legitimate process, but on the cognitive sphere added by public debate.

The problem is not with listing important capabilities, but with insisting on one predetermined canonical list of capabilities, chosen by theorists without any general social discussion or public reasoning. To have such a fixed list, emanating entirely from pure theory, is to deny the possibility of fruitful public participation on what should be included and why (Sen, 2004: 77).

What I am against is the fixing of a cemented list of capabilities, which is absolutely complete (nothing could be added to it) and totally fixed (it could not respond to public reasoning and to the formation of social values). (...) But pure theory cannot "freeze" a list of capabilities for all societies for all time to come, irrespective of what the citizens come to understand and value. That would be not only a denial of the reach of democracy, but also a misunderstanding of what pure theory can do, completely divorced from the particular social reality that any particular society faces (Sen, 2004: 77).

4 "to insist in a fixed forever list of capabilities would deny the possibility of progress in social understanding and also go against the productive role of public discussion, social agitation, and open debates" (Sen, 2004: 80) 
As can be gathered from what has been observed up to here, in works as Development and Freedom (2000) Sen seems to place procedural virtues above epistemic ones, stressing the advantages of employing tools legitimized by the fact that the agents under study were involved as opposed to the exclusive involvement of "experts". Somehow, Sen seems willing to renounce to some epistemic component or pattern because he fears to fall into technocratic stances. That alleged relinquishment, however, must be interpreted as a question. The question posed by Sen is the following: how to democratize the process of devising instruments to measure capabilities, not underestimating expert knowledge and presuming the democratic procedure displays enough epistemic value as to justify those strategies.

This presumed inclination in favour of the procedural issue at the expense of the epistemic value witnessed in Development and Freedom (Sen, 2000), reappears in other works such as Democracy as a Universal Value (1999), or in articles as "Dialogue, capabilities lists, and public reason: continuing the conversation"(2004) that witness to the compatibility between procedural and epistemic value in democratic decisions. They also emphasize the relevance of public deliberation at the cognitive level when some need or any kind of valuable life must be defined.

\subsection{Capabilities and Rights}

Within the context provided by arguments that attribute procedural and epistemic value to democratic decisions it is fitting to ask what contribution -if any- the capabilities approach can make to the grounding of human rights.

When discussing the rights that shape citizenship, some thinkers distinguish between first generation rights (civil and political) and second generation ones) economic, social and cultural). We agree with Sen, however, that full implementation of civil and political rights is unattainable within a framework of non-fulfilment of economic, social and cultural rights. All human rights are universal, indivisible and interdependent, and interrelated (Vienna Declaration: World Conference on Human Rights, Vienna 1993). Consequently, it proves impossible to establish a hierarchy of rights or leave out some rights in order to promote others. Contrariwise, specifying the reach of economic, social and cultural rights is a key tool for empowerment and implementation of civil and political rights. That is why it is important to devise strategies for participatory measurements that will open the way to define lists of capabilities that allow to gauge the reach of civil and political rights as well as economic, social and cultural ones.

"Both the understanding of human rights and of the adequacy of a list of basic capabilities, I would argue, are intimately linked with the reach of public discussion between persons and across borders. The viability and universality of human rights and of an acceptable specification of capabilities are dependent on their ability to survive open critical scrutiny in public reasoning" (Sen 2005: 163).
Along this line, the inclusion in the Universal Declaration of Human Rights of "a far wider list of freedoms and recognitions, which besides including basic political rights, adds the right to work, to education, protection from unemployment and poverty, the right to trade-union association and even the right to a fair salary (...) is a radical step forward compared to the narrow scope of the American Declaration, 1776 and the French Declaration, 1789" (Sen, 2011: 412).

\subsection{Towards an Acknowledgment of Obstacles}

Acknowledging both the virtues of deliberative democracy and the possibility of transferring them to the design of a list of capabilities, following democratic procedures does not mean such processes are free from difficulties.

One of the greatest obstacles encountered by this paradigm is caused by differences in abilities or competence at expression among participants in deliberations to argue and defend their stances. It is a demanding type of communication and some critics hold that it may reproduce inequalities (Mansbridge, 1992). In view of this problem, Habermas states that arguing is connected to daily routines of providing and demanding reasons. He claims that in everyday communication agents already move among reasons, clear up validity assertions, learn from each other and solve problems since in the very act of expecting to be understood about something "they cannot avoid mutually expounding claims of validity for their assertions" (Habermas, 2009: 145).

The ideal of deliberative democracy requires including everybody under conditions of freedom and equity; consequently, it intends to ensure that those in situations of asymmetries of power can voice their opinion. It is worth noting that it is not the rules of discourse that spell disadvantage for the weakest; it is incumbent powers that devise asymmetrical and unequal relationships in social life (Reigadas, 2010). Consequently, acknowledging the difficulties involved in guaranteeing equal conditions in public debates does not imply conferring ontological symmetry to reality and discourse. Discourse constitutes a normative instance through which reality may be judged. If discourse proves emancipatory it is precisely because it admits leaving a situation in particular and imagining other settings, thus fostering the chance of critiquing even the conditions in which the very discourse is produced.

Applying it to the definition and eventual delineation of capabilities lists it would prove necessary to produce spaces of deliberation where experts can neutralize such differences. Since although, as alleged by Habermas (2009), they are daily communication practices, these usually are symmetrical situations where people provide and require reasons from each other. As is well known, deliberation conditions are not guaranteed. Differences as to discursive competence happen against a backdrop of differences in life 
experiences and the epistemic wealth of deliberation is caused by the possibility of having access to such experiences in public exchanges.

Another obstacle of the epistemic notion of democracy lies in the cognitive differences between citizens. This poses a couple of problems: one of them is connected to the level of wisdom of each person. It might be deemed convenient to let the wisest persons make the necessary decisions or, in the case of capabilities list to evaluate wellbeing, leave them exclusively in charge of experts. Nevertheless, as maintained by Estlund (2011) in reference to deliberative democracy, there is no guarantee that sages will not privilege their own benefits in detriment of the common good. In that case, if decisions were left in the hands of this sort of aristocracy of sages' dangers would outstrip benefits.

The unfeasibility of reaching consensus is yet another hindrance. Authors who focus on deliberative processes have amply foreseen this problem. When people argue and expound their stances about what they deem fair, they seldom come to an agreement and even when they manage to do so, agreements are not always final; they may later prove more inclusive and based on better reasons (Gutmann and Thompson, 1996; Bohman, 1997; Richardson, 2002; Estlund, 2011).

Problems connected to the unfeasibility of reaching consensus in general move over to the capability approach and pose an array of questions: How to build consensuses about what should be measured? If we assume that this kind of measurements leads toward devising better social policies, what happens if it proves impossible to agree on a list of capabilities? How valid would each list be in view of the fact that the consensus reached is not definite? Must we give up the possibility of comparing poverty conditions if we have different lists?

Based on what we have just said, if no consensus is reached and having to admit that one's position did not win, Estlund (2011) argues that, as opposed to groups of experts or specialists, the democratic process is invested with an epistemic value that may be generally accepted by qualified opinion, without demanding to forsake one's own judgement. This would avoid the issue of rectification, which implies one owns he was mistaken if one's opinions do not coincide with the results of agreements that were democratically arrived at.

Lastly, if the capability approach may be articulated with epistemic proceduralism, it is appropriate to ask: What epistemic value would we demand from public deliberation when devising a list of capabilities with which to assess situations of deprivation? Where would we place its cognitive value? In participation (as held by some supporters of deliberative democracy), or should epistemic value rest on deliberation conditions? The former, which holds that the more individuals who participate there is a larger chance of reaching correct decisions, does not seem appropriate because the number of participants does not guarantee the quality of deliberation and the knowledge generated by these processes is given by the quality of deliberation. The choice seems to be the latter; in that case, the issue will be to sustain epistemic justification, even under non-ideal conditions.

These hurdles that must be overcome by deliberation processes, compounded by the material restrictions typical of every deliberative process -that is, conditioning aspects related to time and location of discussions- require that we continue exploring the connection between democratic processes and the capability approach. It proves essential to reach a balance point between proceduralism and epistemic virtues if we expect to make a significant contribution within poverty-studies.

\section{Conclusions}

Reconstructing the general guidelines of Sen's perspective, which proposes to delineate capability lists of democratic procedures that involve agents whose wellbeing will be measured, with no prior prescription, allowed us to confirm that this perspective shares the basic viewpoints of approaches which support the epistemic value of democracy.

This link, as we noticed above, has moved within Sen's work from a stance that highlighted concern for the legitimacy of measuring instruments, granting further value to the democratic participation of the agents, to another stance that makes room for compatibility between the procedural and the epistemic fields.

In fact, Sen assigns cognitive virtues to deliberation at various levels: on one hand, in a practical dimension because meeting others enables denaturalisation of situations, habits and routines that restrict and limit agents' autonomy and facilitates widening knowledge about rights and, consequently, about the conditions for exercising citizenship. On the other hand, on theoretical and methodological levels since such processes open the way for redefining the valuable and making it measurable.

As shown up to here, the most obvious links between the capability approach and epistemic proceduralism belong in the theoretical level. The challenge for those studying poverty and social needs lies in effectively applying the current ideal notion of deliberative democracy to the definition of needs or capabilities lists which, in turn, provide solid arguments for grounding rights. Without doubt, the challenge is to democratise the process of defining valuable life styles, opening new links between experts and civil society with the purpose of creating new deliberation spaces where restrictions of time and location of discussions typical of any deliberation process may be faced and solved, while simultaneously expanding the boundaries of citizenship.

Citizen activity constitutes the substance of democratic politics. Its implementation would prove impossible in the absence of an institutional device. Such device, however, is dynamic and subject to transformations. Some of the latter may respond to pressure by citizen groups that, somehow, "push" the limits that define the conditions for belonging to a 
society and, in the process, outline the enlargement of rights to democracy.

The epistemic value of deliberation depends on the existence of a framework where everyone can express $\mathrm{him} / \mathrm{herself}$. It is only within such framework that experiences and needs of others can be understood, where each person's experiences may be denaturalised and re-signified. This will permit a novel definition of both needs and capabilities. In this sense, the results of deliberative processes are never impervious to the reality of their participants. Deliberation implies comprehension, shifting to the situation of others preserving particularity without self-effacement, but permitting interpellation. Given these conditions, deliberation may be seen as broadening freedoms, transforming and liberating subjects.

\section{REFERENCES}

[1] Arendt, H. (1958). The Human Condition. USA, University of Chicago Press

[2] Barber, B. (2004). DemocraciaFuerte, Córdoba: Almazara.

[3] Bohman, J. (1997). Public Deliberation. Cambridge: The MIT Press.

[4] Christiano, T. (1996). The rule of the many. Colorado: Westview Press.

[5] Dryzek, J. (2001). Legitimacy and economy in deliberative democracy. Political Theory, 29, October 2001: 651-69.

[6] Elster, J. (1983). Sour Grapes: Studies in the Subversion of Rationality. UK, Cambridge University Press.

[7] Estlund, D. (2008). Democratic Authority: A Philosophical Framework. Princeton, Princeton University Press

[8] Fung, A. y Wright, E. (2003).Deepening democracy. New York: Verso.

[9] Gargarella, R. (1995). El ideal de la democraciadeliberativa en el análisis del sistemarepresentativo.Algunasnotasteóricas y unamiradasobre el caso de la Argentina.RevistaSociedad, $\mathrm{N}^{\circ} 6$, Facultad de CienciasSociales: Universidad de Buenos Aires.

[10] Gutmann, A. y Thompson, D. (1996).Democracy and disagreement. Harvard: Harvard University Press.
[11] Habermas, J. (2009). ¡Ay, Europa!,Pequeños escritos políticos XI, Madrid: Trotta.

[12] Mansbridge, J. (1992). A deliberative theory of interest representation. En Mark Petracca (Eds.), The politics of interest. (pp. 32-57) Oxford: Westview Press.

[13] Nino, C. (1997). La constitución de la democraciadeliberativa. Barcelona: Gedisa.

[14] Pereira, G. (2007). Preferenciasadaptativas: undesafíopara el diseño de laspolíticassociales. ISEGORÍA. Revista de Filosofía Moral y Política. N. ${ }^{\text {o } 36}$, enero-junio 2007: 143-165.

[15] Pérez, S. (2012). La pobrezacomoespacio controversial. Reflexiones en torno a lasdinámicas de cambio conceptual y el progresoepistémico.España: Editorial Académica Española.

[16] Pérez Zafrilla, P. (2009). Democraciadeliberativa: unaapuestapor el valor epistémico de la deliberaciónpública. Revista de Filosofía, Vol. 34, Núm.1:155-173.

[17] Sandel, M. (1982). Liberalism and the Limits of Justice.UK, Cambridge University Press

[18] Rawls, J (1971). A Theory of Justice. USA, Belknap.

[19] Reigadas, M. C. (2010). "La democraciadeliberativa: el arte de la políticamásallá del elitismo y de la democracia". Jornadas de Etica y Ciencia. UCES. Buenos Aires.

[20] Richardson, H. (2002). Democratic autonomy, public reasoning about the ends of policy. Oxford: Oxford University Press.

[21] Sen, A. (2004). "Dialogue, Capabilities List and Public reason" Feminist Economics 10(3), November 2004, 77 - 80.

[22] Sen, A. (1999). Development as Freedom. New York, Oxford University Press.

[23] Sen, A. (1999). "Democracy as a Universal Value." Journal of Democracy 10.3 (1999) 3-17.

[24] Sen, A. (1998). The possibility of social choice. Nobel Lecture, December 8, 1998.

[25] Sen, A. (1997). Bienestar, Justicia y Mercado. Barcelona: Paidós.

[26] Sen, A. (2005). Human rights and capabilities. Journal of Human Development Vol. 6, No. 2, July 2005. United Nations Development Programme.

[27] SEN, A. (2009). The Idea of Justice, Londres, Penguin. 